\title{
Landscape determinants of European roller foraging habitat: implications for the definition of agri- environmental measures for species conservation
}

\author{
Inês Catry ${ }^{1,2,3}$, Joana Marcelino ${ }^{1}$. Aldina M. A. Franco ${ }^{2}$. \\ Francisco Moreira ${ }^{1,3}$
}

\begin{abstract}
Across much of Europe, farmland birds are declining more than those in other habitats. From a conservation perspective, identifying the primary preferred habitats could help improve the foraging conditions of target species and, consequently, enhance their breeding success and survival. Here, we investigated the ranging behaviour and foraging habitat selection of the European roller (Coracias garrulus) during the breeding season in an agricultural landscape of South Iberia. The occurrence of foraging rollers was predicted to gradually increase with decreasing distance from the nest and increasing availability of perches, such as fences and electric wires. Traditional olive groves and stubble fields were positively and negatively associated with the occurrence of rollers, respectively. Additionally, analysis of hunting strikes showed that rollers highly prefer foraging in fallows rather than cereal or stubble fields. Prey surveys revealed that fallows had the highest abundance of grasshoppers, rollers' preferred prey during chick-rearing. Pair home-ranges, obtained from 95\% fixed Kernel estimators averaged 70.9 ha (range $=34-118$ ha) and most foraging trips $(80 \%)$ occurred in the close vicinity of the nest ( $1500 \mathrm{~m})$. Number of chicks fledged was not affected by mean foraging distances travelled during the chickrearing period. Overall, our results suggest that traditional extensive practices of cereal cultivation, with large areas of low-intensity grazed fallows, represent a high-quality
\end{abstract}

1 Centro de Ecologia Aplicada 'Prof. Baeta Neves' and InBio - Rede de Investigação em

Biodiversidade e Biologia Evolutiva, Instituto Superior de Agronomia, Universidade de Lisboa, Lisbon, Portugal

2 School of Environmental Sciences, University of East Anglia, Norwich, UK

3 REN Biodiversity Chair, CIBIO/InBIO - Rede de Investigação em Biodiversidade e Biologia Evolutiva, Universidade do Porto, Vairão, Portugal 
foraging habitat for rollers and should be promoted through agri-environmental schemes within at least 1-km radius from the nest. These recommendations are targeted at the roller, but have been shown to apply broadly to several other steppe-bird species.

Keywords Habitat selection · Farmland landscapes · Coracias garrulus · Home-ranges · Agri-environmental schemes · Iberian Peninsula

\section{Introduction}

Despite its man-made nature, European farmland supports an important community of open-country bird species that have adapted to farming landscapes over thousands of years of agricultural development and expansion (Krebs et al. 1999; Donald et al. 2002). However, in the last decades, agricultural intensification and abandonment of traditional farming practices led to a reduction in both the extent and quality of foraging and breeding habitats for many species and is considered the primary cause of the decline of Europe's farmland bird populations (Donald et al. 2001). In order to halt the ongoing biodiversity loss, voluntary agri-environmental schemes (AES) were implemented through the Common Agricultural Policy (CAP) in the 1990s, but their efficiency in promoting biodiversity varied markedly (Kleijn and Sutherland 2003; Perkins et al. 2011; Whittingham 2011), suggesting incomplete knowledge of wildlife habitat requirements and species' responses to agriculture management. Abundance, quality and distribution of food resources are influenced by habitat quality and availability of foraging patches and are strongly influenced by land-use management (e.g. Wolff 2005). Thus, from a conservation perspective, understanding habitat-species relationships could help to predict how populations would respond to habitat modifications. This could help wild-life managers to evaluate future impacts of agricultural changes and to improve the foraging conditions of target species through the implementation of specific and effective management practices (Sutherland and Green 2004).

The European roller Coracias garrulus (hereafter roller) is a long-distance migratory Coraciiform, included in the EU Birds Directive Annex I that breeds throughout temperate, steppe and Mediterranean zones characterized by reliable warm summer weather (BirdLife International 2016). The European population is still thought to be declining but at a less severe rate than in the recent past, thus the species is classified as Least Concern (BirdLife International 2016). The Iberian Peninsula holds the major fraction of the European subspecies garrulus, classified as Critically Endangered and Vulnerable in the Portuguese and Spanish Red Data Lists, respectively (Madroño et al. 2004; Cabral et al. 2005). Rollers are obligate cavity-nesters using abandoned cavities in trees, fissured rocks or sandy banks to nest (Cramp and Simmons 1988). In southern latitudes, in areas where trees are lacking, nests are frequently located in human buildings and nest-boxes (Catry et al. 2011; Rodr' iguez et al. 2011). The main causes of the recent widespread decline include the loss of suitable habitat due to changing agricultural practices (which affect foraging habitat quality and extent), loss of nest sites and sustained persecution along the migration routes (Kovacs et al. 2008; BirdLife International 2016). The species has only recently been recognised as in need of specific conservation actions (Kovacs et al. 2008). Whilst detailed knowledge of a species habitat needs is essential in developing effective management plans, the roller's habitat foraging preferences and home-range sizes are still poorly known 
(Kovacs et al. 2008) as all previously published studies focus on breeding habitat selection (e.g. Avilés and Parejo 2004; Bouvier et al. 2014; Kiss et al. 2016).

Habitat selection is driven by several forces, but food availability is often the primary one. To maximize foraging success, individuals are more likely to select habitats in which the preferred prey are abundant and are easily located and caught (Stephens and Krebs 1986). Moreover, for central place foragers, such as the roller, home ranges are determined largely by the number of feeding places used and by the distance that birds travel between nest-sites and foraging areas (Johst et al. 2001; Catry et al. 2012). In this paper, we investigated the ranging behaviour and foraging habitat selection of rollers during the breeding season and identify which habitat and landscape features are associated with rollers' foraging activity. We also surveyed the abundance of main prey in potential foraging habitats to assess if preferred foraging habitats are those showing the highest prey availability. Finally, we investigated ranging behaviour of rollers through the evaluation of home-range size and maximum hunting distances of breeding pairs and its influence on breeding success. Overall, this study aimed to identify management recommendations to increase the effectiveness of future conservation interventions and integrate appropriate actions into agri-environmental policies.

\section{Methods}

\section{Study area}

The study was conducted in the Castro Verde Special Protection Area (SPA, $37^{\circ} 43^{\circ} \mathrm{N}$, $7^{\circ} 57^{\circ} \mathrm{W}$ ), the most important area for the conservation of steppe bird species in Portugal. With 85,000 ha, the region harbours more than $80 \%$ of the Portuguese roller population (Catry et al. 2011), which predominantly breed in old rural buildings and artificial nesting structures, frequently in lesser kestrel (Falco naumanni) colonies. The landscape is dominated by extensive cereal cultivation with a mixture of cereals and fallows, leguminous crops and ploughed fields. Soils are thin and poor for agricultural yields and thus are kept under a low-intensity rotational system in which after 2 years of cereal cultivation the land is left uncultivated for 3-5 years (fallows). Therefore, the landscape is dominated by fallow fields (usually over $50 \%$ of the area), used only for livestock rearing. Other habitats include small areas of open holm-oak (Quercus ilex) "montado", olive groves (Olea europaea), introduced Eucalyptus trees, shrubby vegetation and orchards.

\section{Foraging habitat selection, home-range estimation and breeding success}

The foraging behaviour of twelve roller pairs (5 in 2013 and 7 in 2014) was investigated from early June to early July, during the chick rearing period. From high vantage points, we performed observations of parent foraging bouts. Individuals were followed from the nest to the location of foraging attempts and returning, enabling the attribution of each roller to a nest. Rollers are primarily sit-and-wait predators that use perch sites from which to scan for prey. The exact location where a successful strike took place was mapped along with perch and habitat type. Observation periods occurred between 07h00-11h30 and 16h00-19h30.

To identify which habitat and landscape variables were associated with foraging rollers during the nestling period, we assigned each foraging location to a grid of 4-ha cells 
$(\mathrm{n}=57)$ within a $1 \mathrm{~km}$ radius centred at each nest (this buffer contained [95\% of all foraging observations). Field surveys and aerial photos were used to build habitat maps in the buffers (habitat categories: fallow, cereal, stubble, ploughed fields, orchards, vineyards, water, olive groves, pine and holm oak recent forestations, open holm oaks and shrub) and to map the occurrence of relevant landscape features that could be used as perches (presence of trees, rocks, fences, power lines). All information was then integrated in a Geographic Information System using Quantum GIS 2.12 (QGIS Development Team $2015)$ to estimate, for each cell, the relative area of each habitat (\%), length of telephone and electricity power lines (m), length of fences (m) and distance from the centre of the cell to the nest $(\mathrm{m})$. Additionally, habitat edge density, measured as the sum of edge lengths (m) of all habitat patches, was estimated. Information on grazing pressure (number of livestock per unit of fallow area) was not available and thus not included.

Rollers appear sexually monochromatic to humans (Avilés 2006) making it hard to distinguish between sexes when performing foraging observations. Therefore, we identified the individual home-range areas of each roller pair using 95\% fixed Kernel estimators (Worton 1989), encompassing the locations obtained for both sexes during chick-rearing. We used the R package adehabitat (Calenge 2006) to compute kernel estimators and Quantum GIS 2.12 (QGIS Development Team 2015) to calculate home-range sizes. To ensure independence between observations, we separated each observation of the same bird by an interval of at least $10 \mathrm{~min}$. The estimation of this interval was based on behavioural observations: on average, one adult roller delivers food every $5 \mathrm{~min}$ to its offspring (mean prey delivery per hour is $13.6 \pm 5.3 ; \mathrm{n}=45 \mathrm{~h}$ of observation, I. Catry, unpublished data).

Breeding success (number of chicks fledged) of studied roller pairs was estimated from nest monitoring performed on a weekly basis.

\section{Statistical analyses}

To analyse the influence of habitat and landscape features on rollers' foraging decisions we used generalized linear mixed models (GLMM) with a binomial error distribution and a logit-link function. We defined a binary dichotomous response variable of 0 if adult rollers were absent from a given cell and 1 if rollers were present foraging, pooling the data for the chick rearing period. Habitat and landscape variables included as predictors are presented in Table S1. Nest identity was included as a random factor. Habitat variables were grouped into six classes (fallow, cereal, stubble, olive groves, recent forestations and other) and classified with the Braun-Blanquet vegetation scale: (0) absent or present in less than $1 \%$ of the square; (1) present in $1-5 \%$ of the square; (2) $6-25 \%$ of the square; (3) $26-50 \%$ of the square; (4) $51-75 \%$ of the square or (5) $76-100 \%$ of the square. As the scales of the variables varied considerably, all variables were standardized (centred and scaled). Correlation between explanatory variables was not large $(|\mathrm{r}| \backslash 0.5)$ for all combinations. We used multi-model inference and model averaging based on Burnham and Anderson (2002), with the package MuMIn (Bartón 2015) which uses Akaike information criterion (AIC) to rank all possible parameter subset models. Sample size-corrected AIC (AICc), Akaike

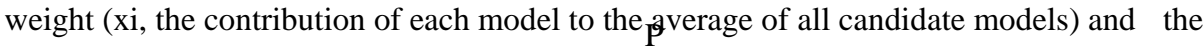
relative importance of each predictor variable ( $x i$ across all the models in the set where the variable occurs) were computed. Multi-model inference and model averaging were justified by the uncertainty in model choice given the number of candidate models with DAICc \ 2 (Table 1). Model-averaged estimates of the parameters were obtained by computing means and $95 \%$ confidence intervals $(95 \% \mathrm{CI})$ using the weighted average of 
Table 1 Top-competing (DAICc \2) logistic regression models of variables affecting the occurrence of foraging rollers during the chick-rearing period in Portugal

\begin{tabular}{|c|c|c|c|c|}
\hline Model & $\mathrm{k}$ & $\mathrm{AICc}$ & DAICc & AICc xi \\
\hline Dist? fences? lines ? olive ? stubble & 7 & 536.6 & 0.00 & 0.11 \\
\hline Dist ? fences ? lines ? olive ? stubble? habedge & 8 & 537.8 & 1.19 & 0.06 \\
\hline Dist ? fences ? lines ? olive ? stubble? fallow & 8 & 537.9 & 1.30 & 0.06 \\
\hline Dist ? fences? lines? fallow ? olive ? stubble ? cereal & 9 & 538.0 & 1.42 & 0.05 \\
\hline Dist? fences? lines ? olive? stubble ? cereal ? habedge & 9 & 538.2 & 1.55 & 0.05 \\
\hline Dist? fences? lines? fallow ? olive? stubble? fallow? habedge & 8 & 538.3 & 1.66 & 0.05 \\
\hline Dist ? fences ? lines? olive? stubble? forestations & 8 & 538.7 & 2.05 & 0.04 \\
\hline
\end{tabular}

Models are ranked according to the Akaike information criterion, corrected for small sample sizes (AICc). The DAICc indicates AICc differences between a particular model and the best-fitting model. Akaike weights (xi), which indicate the contribution of each model to the average of all candidate models, and the number of parameters $(\mathrm{k})$ are also presented. Habitat variables (fallow, cereal, stubble, olive groves, recent forestations and other) were classified with the Braun-Blanquet vegetation scale. Dist distance to the nest $(\mathrm{m})$, fences length of fences, lines length of telephone and electricity power lines $(\mathrm{m})$, habedge habitat edge density (m)

the corresponding coefficient in all models in the candidate set (cumulative sum of weights 10.95). Where the 95\% CI for an effect size did not span zero, this effect could be considered statistically significant at the 5\% level (Burnham and Anderson 2002). Moreover, we evaluated accuracy of the prediction with the multimodel inferred coefficients using the area under the curve (AUC, Manel et al. 2001).

Given the high availability of fallow land around nests (ca. 75\%) which could provide misleading assessments of habitat selection in the logistic model, we analysed foraging decisions of rollers using all observations of successful strikes $(n=164)$ performed by rollers perched on fences. Fences were the most frequently used perch by rollers and commonly establish the border between two different habitats, being thus ideal to investigate habitat preferences. Since fallow land occupied the largest proportion of habitat around surveyed pairs of rollers, we were only able to compare habitat preference of fallow against other habitats: cereal and stubble fields, olive groves and other. We also considered fire-breaks (ploughed gaps without vegetation to slow or stop the progress of fires) as one habitat category, when the stripe-width of fire-breaks along the fences exceeded six meters. We used Chi square tests (Yates corrected) to compare pair-wise habitat selection of foraging rollers with the expected values under a "no preference"' null hypothesis.

We conducted all analysis with R software (R Development Core Team 2015).

\section{Food availability: grasshopper counts}

During the chick rearing period, rollers feed their chicks mainly with large grasshoppers (I. Catry, unpublished data). To estimate prey availability in habitats used by foraging rollers, we performed 297 walked transects (transect length $=25 \mathrm{~m}$ ) along fences within the $1 \mathrm{~km}$ buffer around nest-sites during the chick-rearing period, recording the number of grasshoppers observed in a band of $50 \mathrm{~cm}$ in each side of the transect. Habitat types included habitats used by foraging rollers, according to their availability $(\mathrm{n}=153,37,26$, 8 and 73 transects in fallows, cereal, stubble fields, olive groves and fire-breaks, respectively). Comparisons of prey abundance across habitats were assessed using KruskalWallis followed by Tukey post hoc tests. 
Fig. 1 Predicted probability of occurrence of foraging rollers during the chick-rearing period in relation toc significant habitat and landscape variables. Probabilities (solid lines) and their $95 \%$ credible intervals (shaded area) were predicted by the model-averaged coefficients using the actual range of values for the predictor variable of interest, and mean values for the other variables. Habitat variables (fallow, cereal, stubble, olive groves, recent forestations and other) were classified with the Braun-Blanquet vegetation scale (see "Methods" section)

\section{Results}

\section{Foraging habitat selection and prey abundance}

Model averaging revealed that the occurrence of foraging rollers was driven by distance to the nest, but landscape and habitat variables around nests also played a significant role (Tables 1, 2; Fig. 1). Distance to the nest, length of fences and telephone/power lines and proportion of stubbles and olive groves were all included in top-models with high selection probabilities (Rxi [ 0.90 , Tables 1, 2). The $95 \%$ confidence intervals surrounding multimodel weighted coefficients for the remaining predictor variables spanned zero, indicating that these factors had limited effect in predicting the occurrence of foraging rollers (Table 2). Overall, probability of occurrence of foraging rollers was predicted to gradually decrease with increasing distances from the nest and with increasing area of stubble fields (Fig. 1). In contrast, probability of roller occurrence was predicted to rise with increasing length of fences and telephone/power lines and with increasing proportions of olive grove cover (Fig. 1). The models had good overall predictive ability according to the AUC value $(0.82)$, showing a useful application of the model predictions.

Analysis of hunting strikes showed that rollers preferred fallows over cereal fields $\left(\mathrm{v}_{\nexists \mathrm{lb}}^{2}=34.1, P \backslash 0.001\right)$, stubbles $\left(\mathrm{v}^{2}{ }_{\mathrm{ap}}=9.3, P \backslash 0.01\right)$, fire-breaks $\left(\mathrm{v}_{\mathrm{ap}}^{2}=5.4\right.$, $P \backslash 0.05)$ and otherhabitats $\left(\mathrm{v}^{2}{ }_{\mathrm{dp}}=5.4, P \backslash 0.05\right.$, Fig. 2). Nosignificantdifferences were found when comparing fallows and olive groves $\left(\mathrm{v}_{\partial \mathrm{ll}}^{2}=1.0, P=0.31\right.$, Fig. 2$)$.

Results from walked transects revealed that grasshoppers were significantly more abundant in fallows compared to cereals, stubbles and fire-breaks, whilst lowest

Table 2 Model-averaged parameter estimates (coefficient), unconditional standard errors (SE) and 95\% confidence intervals (CI) for the predictors of foraging roller occurrence during the chick-rearing period

\begin{tabular}{lcccrr}
\hline Predictor & Coefficient & Unconditional SE & $95 \%$ lower & 95\% upper & xi \\
\hline Distance nest & 21.00 & 0.12 & 21.24 & 20.75 & $>0.99$ \\
Fences length & 0.50 & 0.11 & 0.28 & 0.73 & $>0.99$ \\
Lines length & 0.31 & 0.14 & 0.08 & 0.57 & 0.96 \\
Fallow & 0.05 & 0.16 & -0.31 & 0.61 & 0.36 \\
Cereal & -0.06 & 0.16 & -0.55 & 0.25 & 0.38 \\
Stubble & 20.44 & 0.21 & 20.84 & 20.09 & 0.95 \\
Forestations & -0.02 & 0.07 & -0.29 & 0.28 & 0.26 \\
Olive groves & 0.28 & 0.13 & 0.08 & 0.53 & 0.93 \\
Other habitats & -0.03 & 0.10 & -0.41 & 0.23 & 0.31 \\
Habitat edge density & 0.10 & 0.16 & -0.12 & 0.56 & 0.47 \\
\hline
\end{tabular}

$\mathrm{P}$ xi for each predictor variable shows the sums of Akaike weights for all possible models in which the predictor variable was included and reflects the relative importance of each variable. Factors are considered to have a significant influence on effect size where $95 \%$ CI for estimated coefficients do not span zero; these cases are indicated in bold 

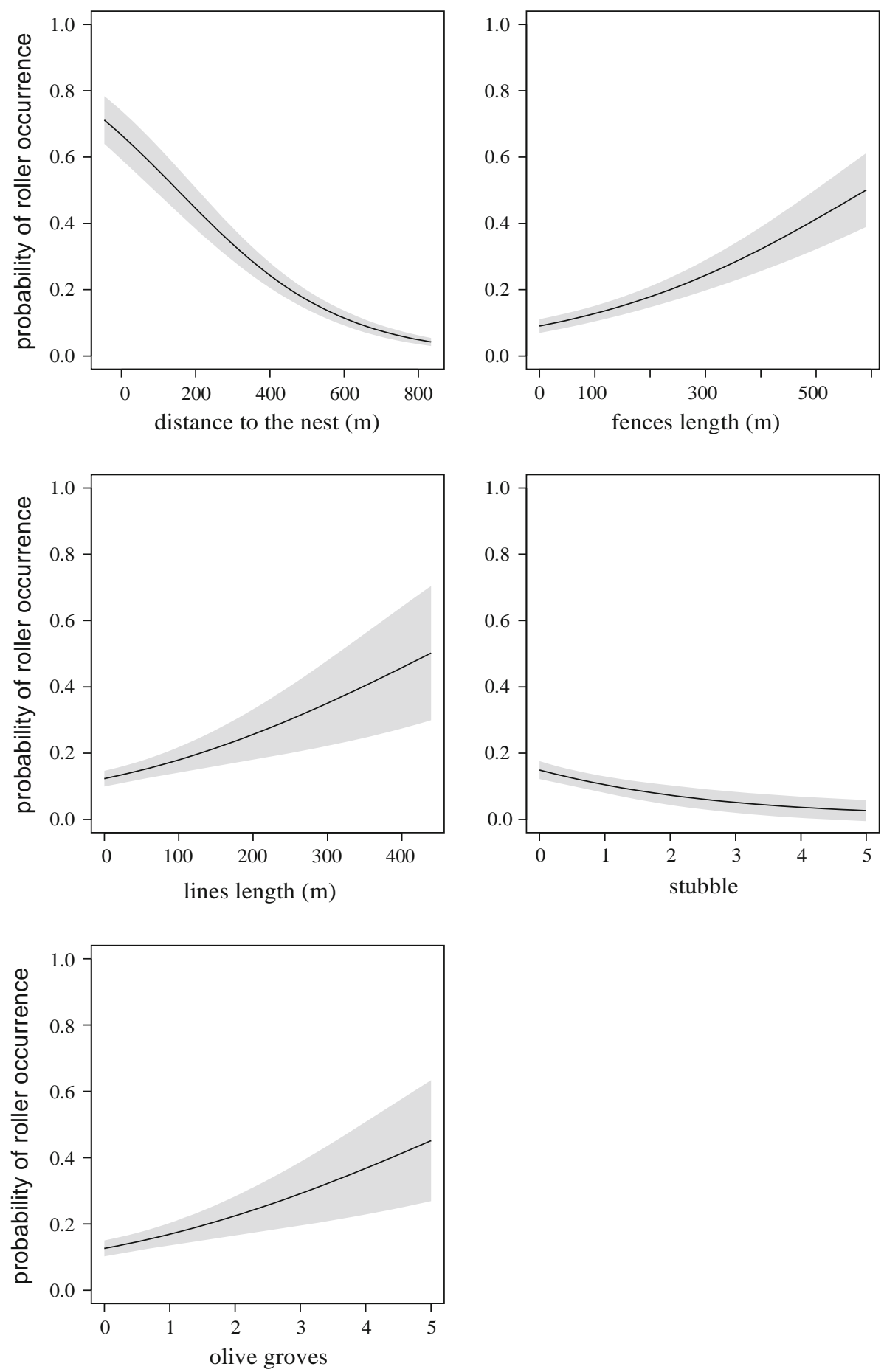


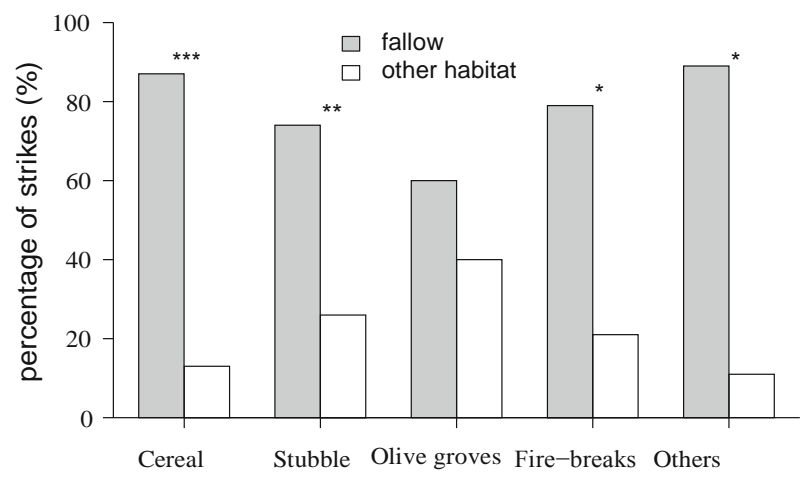

Fig. 2 Foraging habitat selection by rollers during the chick rearing period in the Castro Verde SPA. Foraging decisions of perched rollers were recorded when birds used fences dividing two different habitats (fallow versus other). Bars represent the percentage of strikes recorded in fallows (grey) and in alternative habitats ( white) by foraging rollers $(\mathrm{n}=164)$. Significant values for comparisons between habitat types are shown (*P\0.05; **P $\backslash 0.01 ; * * * P \backslash 0.001)$

abundances were found in cereal and stubble fields $\left(\mathrm{v}_{\gamma 4 \mathrm{p}}^{2}=128.1, P \backslash 0.001\right.$, followed by Tukey post hoc tests, Fig. 3).

\section{Home-ranges, foraging distances and breeding success}

On average, each pair was observed during $7.1 \pm 1.3$ days $(\min -\max =5-9)$ in order to achieve a minimum of 40 foraging locations per pair (average of $64.6 \pm 11.1$, min$\max =42-83$, total $=762$ ). During the chick-rearing periods of 2013 and 2014, mean home-range size of 12 roller pairs obtained using 95\% fixed Kernel estimators was 70.9 ha (range $=34.3-118$, Fig. 4). The degree of overlap in home-ranges of neighbouring pairs ranged from 12 to $87 \%$ (Fig. 4). During chick provisioning, most adults foraged in the proximity of the nest: $80 \%$ of all foraging observations were located within a radius of $500 \mathrm{~m}$ around the nest (Fig. 5). Mean distance travelled by roller pairs $(\mathrm{n}=12)$ to foraging grounds averaged $274.2 \pm 77.9$ meters (mean range $=136.3-404.4$ ).

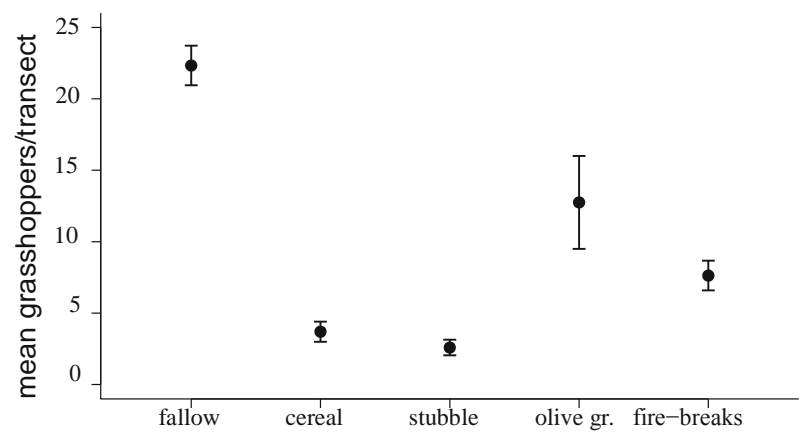

Fig. 3 Mean $( \pm$ SE) number of grasshoppers surveyed in $2591 \mathrm{~m}$ transects in fallow, cereal, stubble, olive groves and fire-break areas around roller nests $(n=153,37,26,8$ and 73 transects, respectively) 
Fig. 4 Home-ranges of twelve pairs of rollers during the 2013 and 2014 chick-rearing seasons in Castro Verde, south Portugal. Shaded areas represent the $95 \%$ fixed Kernel contours and black stars the location of nests. S1-S5 indicate the five areas where foraging observations occurred. The degree of overlap in homeranges of neighbouring pairs ( $S 1$ and $S 2$ ) ranged from 12 to $87 \%$

\section{$2013 \quad 2014$}

S1

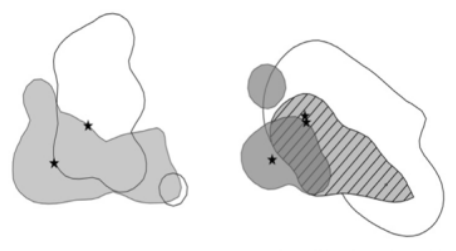

S2

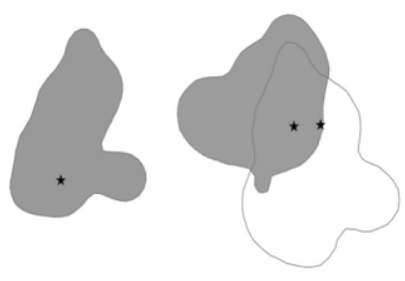

S3
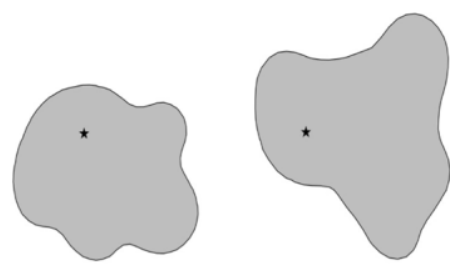

S4

S5
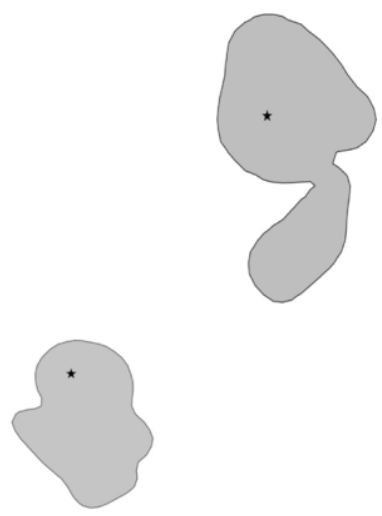

$0 \quad 500 \quad 1000 \mathrm{~m}$

Breeding success (mean number of fledglings $=4.8 \pm 0.9$ ) of surveyed rollers in both years were not affected by mean foraging distances travelled $\left(\mathrm{F}_{2,9}=0.81, P=0.48\right)$ nor home-range sizes $\left(\mathrm{F}_{2,9}=0.99, P=0.41\right)$. 


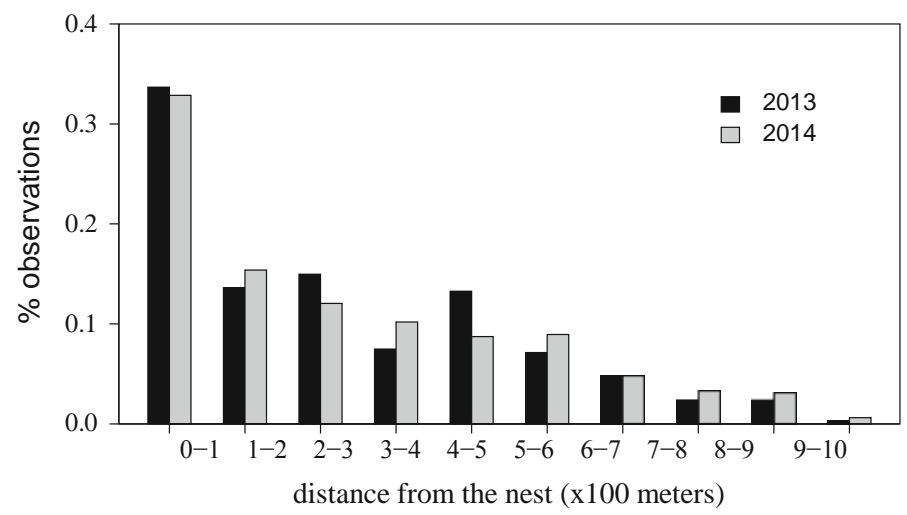

Fig. 5 Distribution of foraging locations of rollers in relation to the distance from the nest in Castro Verde in 2013 and 2014

\section{Discussion}

To our knowledge this is the first study looking at ranging behaviour and foraging habitat selection of breeding rollers. Previous studies assessed habitat preference of rollers based on the comparison of habitat characteristics around occupied and non-occupied nests (Catry et al. 2011; Rodr'́1guez et al. 2011; Bouvier et al. 2014; Kiss et al. 2016) or based in comparisons of breeding success amongst different habitats (Avilés and Parejo 2004; Kiss et al. 2014). Rollers are obligate cavity breeders and strongly limited by nest-site availability hence habitat use during the breeding period will likely be constrained by the location of nest-sites.

The probability of occurrence of rollers foraging was not affected by the quantity of fallow area in the vicinity of the nest. In our study area, fallows are the most widespread habitat and occupy the largest proportion of habitat within the $1 \mathrm{~km}$ radius buffer around nest-sites (ca. 75\%), likely explaining the absence of this variable in the best retained models. Nonetheless, fine-tuned analyses of hunting strikes (see methods) showed that individuals actively selected fallows when they had the chance to choose between this and other habitats. This preference was probably due to the high abundance of grasshoppers, the preferred prey of rollers as revealed by video recordings of adults feeding chicks (I. Catry, unpublished data), in this habitat type. The probability of finding a foraging roller decreased with increasing proportion of stubbles. Other studies have shown that, because stubble vegetation is short, prey accessibility increases after cutting (e.g. Catry et al. 2014) and other studies reported that freshly mown meadows attracted rollers (e.g. Kiss et al. 2016). Nonetheless, the avoidance of stubbles found in this study is likely due to the ephemeral effects of cereal cutting showing a rapid drop off in the abundance of grasshoppers and making the expected intake rate in stubbles the lowest amongst most representative habitats (Catry et al. 2014), which is corroborated by the fact that this habitat type had the lowest prey abundance. Results from hunting observations also suggest that cereal was avoided when fallow was present. The lower prey abundance and tall vegetation may limit the accessibility of Orthoptera to rollers in cereal fields. Olive groves were positively associated with the probability of occurrence of foraging rollers and the analysis of hunting strikes suggest that this habitat was used in proportion to its availability. Traditional olive groves in the study site have old trees in low density and provide 
high perches from which rollers can scan for prey. Additionally, olive groves are relatively rich in prey likely justifying their use by foraging rollers. Large fire-breaks were also passed over when fallows were available, likely due to vegetation removal and consequent low prey abundance. Overall, our results agree with previous findings from breeding habitat selection studies that highlight the preference for meadows, fallows and pastures (Avilés and Parejo 2004; Sackl et al. 2004; Rodríguez et al. 2011; Bouvier et al. 2014). Moreover, foraging habitats selected by rollers highly overlaps those selected by lesser kestrels, a colonial species with similar dietary and breeding requirements (Catry et al. 2012, 2014). Hence, conservation measures that benefit one species are likely to benefit the other.

As sit-and-wait predators, rollers preferred areas with large cumulative length of fences and telegraph/power lines from which to scan for prey. In the last decades, changes in farming management (namely less manpower due to rural depopulation) transformed the character of the landscape around Castro Verde, with fences delineating most of the field parcels. Although representing a threat to other endangered steppe bird species (mortality due to the risk of collision; e.g. Burnside et al. 2012), the proliferation of fences in such an open landscape seems to benefit foraging rollers, allowing individuals to hunt in the proximity of their nests. Power lines were apparently preferred to fences when close to the nests (pers. obs.), likely due to their height which enables foraging rollers to scan a larger area.

Differences in patch selection and home-range size may be related to habitat quality, perch availability, predation or competition pressure (Brown and Morgan 1995; Collister 2007). Although there was some variation among pairs in home-ranges and distances travelled to feed the offspring, breeding success was not affected by the length of foraging trips nor home-range size, suggesting good quality foraging areas occur around nests. The smallest home-range $(25 \mathrm{ha})$ and lowest mean hunting distance $($ mean $=136 \mathrm{~m}$ ) were recorded for a pair breeding in a nest-box fixed to an electric pylon surrounded exclusively by fallow land. Rollers have formerly been described as aggressively territorial, solitary breeders (Samwald and Štumberger 1997). Although intraspecific interactions (e.g. an adult defending a food patch acting aggressively towards intruders) were observed frequently, home-ranges of neighbouring pairs overlapped considerably, corroborating previous observations of breeding clusters (Kovacs et al. 2008).

\section{Management implications}

The traditional cereal-steppe landscape of the Castro Verde SPA offers a high-quality foraging habitat for rollers as suggested by the high breeding success recorded. In Portugal, eight SPAs have been designated for the conservation of the roller, but few pairs remain outside the Castro Verde SPA where the species is relatively abundant and increasing (Catry et al. 2011). Declines elsewhere are likely due to large habitat losses suffered in the last decades, especially steep declines in the extent of fallow land (Pinto et al. 2005; Costa et al. 2003; Catry et al. 2011). Fallows are crucial for grassland bird conservation (e.g. Bota et al. 2005) and are maintained in Portugal due to the implementation, since 1995, of agrienvironmental schemes (Reg. CE 2078/92) and LIFE-Nature programmes (LIFE) that promote favourable habitat for a range of steppe-bird species. Nonetheless, fallows are highly vulnerable to changing farming practices and are threatened by land abandonment and afforestation of agricultural areas (Reino et al. 2010). In addition, grazing pressure greatly influences invertebrate occurrence and accessibility (Lepley et al. 2000) and previous work in the area showed low prey availability in heavily grazed fallows (Tschirley 
2013). Increasing grazing pressure and replacement of traditional systems of extensive sheep grazing by more rewarding cattle production systems (Reino et al. 2010) may jeopardize the preferred foraging areas of rollers. Therefore, the maintenance of low levels of grazing and the implementation of non-grazed patches, in-field strips or field margins (Rodr'1guez et al. 2006), benefit diverse arthropod populations (Catry et al. 2012). Given the low quality of stubble fields as foraging habitat, cereal fields should be harvested as late as possible and starting from patches farthest from nest-sites, as recommended for lesser kestrels (Catry et al. 2012). Fire-breaks around fields are frequently created along fences and, although important to prevent fires, they could be equally effective if present on one side of the fence only, to reduce the detrimental impacts of reduced vegetation on arthropod abundance. Alternatively, the introduction of unmowed field margins between fences and fire-breaks has the potential to help increase prey abundance for foraging rollers.

In the Castro Verde SPA, rollers have benefited from the provisioning of extra cavities, such as opened holes in adobe-built structures and artificial nest-sites (Catry et al. 2011). Approximately $40 \%$ of the roller population uses artificial nests; thus effective conservation planning should promote the maintenance of large areas of fallows with low-intensity grazing with perches around existing nests (in $1 \mathrm{~km}$ buffer as suggested by home-range analysis) and especially in the vicinity of new artificial nest-sites. Overall, future conservation of Iberian populations relies on the maintenance of steppe-like habitat areas promoted by the traditional extensive practices of cereal cultivation under a rotational system which has also been shown to benefit other target steppe-bird species (Catry et al. 2012; Santana et al. 2014).

Acknowledgements Thanks are due to Teresa Catry for helping during fieldwork. This work is funded by FEDER funds through the Operational Programme for Competitiveness Factors-COMPETE and by National Funds through FCT_Foundation for Science and Technology under the UID/BIA/50027/2013 and POCI-01-0145-FEDER-006821. I.C. benefited from post-doctoral grants from Fundação para a Ciência e Tecnologia (SFRH/BPD/76514/2011 and SFRH/BPD/102637/2014).

\section{References}

Avilés JM (2006) Carraca europea-Coracias garrulus. In: Carrascal LM, Salvador A (eds) Enciclopedia Virtual de los Vertebrados Españoles. Museo Nacional de Ciencias Naturales. http://www. vertebradosibericos.org

Avilés JM, Parejo D (2004) Farming practices and Roller Coracias garrulus conservation in south-west Spain. Bird Conserv Int 14:173-181

Bartón K (2015) MuMIn: multi-model inference. R-package, version 1.15.1. https://cran.r-project.org/web/ packages/MuMIn/

BirdLife International (2016) Species factsheet: Coracias garrulus. http://www.birdlife.org. Accessed 22 Feb 2016

Bota G, Morales MB, Mañosa S, Camprodon J (2005) Ecology and conservation of steppe-land birds. Lynx Edicions \& Centre Tecnologic Forestal de Catalunya, Barcelona

Bouvier JC, Muller I, Génard M, Lescourret F, Lavigne C (2014) Nest-site and landscape characteristics affect the distribution of breeding pairs of European rollers Coracias garullus in an agricultural area of southeastern France. Acta Ornithol 49:23-32

Brown JS, Morgan RA (1995) Effects of foraging behavior and spatial scale on diet selectivity: a test with fox squirrels. Oikos 74:122-136

Burnham KP, Anderson DR (2002) Model Selection and multimodel inference: a practical informationtheoretic approach. Springer, New York

Burnside RJ, Carter I, Dawes A, Waters D, Lock L, Goriup P, Székely T (2012) The UK great bustard Otis tarda reintroduction trial: a 5-year progress report. Oryx 46:112-121 
Cabral MJ, Almeida J, Almeida PR, Dellinger T, Ferrand de Almeida N, Oliveira ME, Palmeirim JM, Queiroz AL, Rogado L, Santos-Reis M (2005) Livro Vermelho dos Vertebrados de Portugal. Instituto da Conservação da Natureza, Lisbon

Calenge C (2006) The package adehabitat for the R software: a tool for the analysis of space and habitat use by animals. Ecol Mod 197:516-519

Catry I, Silva JP, Pereira A, Cavaco A, Cardoso A, Martins A, Delgado A, Sanches AR, Santos A, Estanque B, Franco C, Cruz CM, Pacheco C, Conde C, Leitão D, Pereira E, Matilde E, Abegão F, Moital F, Romba F (2011) Distribution and population trends of the European roller in pseudo-steppe areas of Portugal: results from a census in sixteen SPAs and IBAs. Airo 21:3-14

Catry I, Amano T, Franco AMA, Sutherland WJ (2012) Influence of spatial and temporal dynamics of agricultural practices on the lesser kestrel. J Appl Ecol 49:99-108

Catry I, Franco AMA, Moreira F (2014) Easy but ephemeral food: exploring the trade-offs of agricultural practices in the foraging decisions of Lesser Kestrels on farmland. Bird Study 61:447-456

Collister DM (2007) Territory size and foraging habitat of Loggerhead Shrikes (Lanius ludovicianus) in Southeastern Alberta. J Raptor Res 41:130-138

Costa LT, Nunes M, Geraldes P, Costa H (2003) Zonas Importantes para as Aves em Portugal. Sociedade Portuguesa para o Estudo das Aves, Lisbon

Cramp S, Simmons KEL (1988) The birds of the Western Paleartic, vol V. Oxford University Press, Oxford

Donald PF, Green RE, Heath MF (2001) Agricultural intensification and the collapse of Europe's farmland bird populations. Proc R Soc Lond B 268:25-29

Donald PF, Pisano G, Rayment MD, Pain DJ (2002) Review: the Common Agricultural Policy, EU enlargement and the conservation of Europe's farmland birds. Agric Ecosyst Environ 89:167-182

Johst K, Brandl R, Pfeifer R (2001) Foraging in a patchy and dynamic landscape: human land us and the white stork. Ecol Appl 11:60-69

Kiss O, Elek Z, Moskát C (2014) High breeding performance of European rollers Coracias garrulus in heterogeneous farmland habitat in southern Hungary. Bird Study 61:496-505

Kiss O, Tokody B, Deák B, Moskát C (2016) Increased landscape heterogeneity supports the conservation of European rollers (Coracias garrulus) in southern Hungary. J Nat Conserv 29:97-104

Kleijn D, Sutherland WJ (2003) How effective are European agri-environment schemes in conserving and promoting biodiversity? J Appl Ecol 40:947-969

Kovacs A, Barov B, Orhun C, Gallo-Orsi U (2008) International species action plan for the European roller Coracias garrulus garrulus. http://ec.europa.eu/environment/nature/conservation/wildbirds/action_ plans/docs/coracias_garrulus_garrulus.pdf. Accessed 2 Feb 2016

Krebs JR, Wilson JD, Bradbury RB, Siriwardena GM (1999) The second silent spring. Nature 400:611-612

Lepley M, Brun L, Foucart A, Pilard P (2000) Régime et comportement alimentaires du falcon crecerellette Falco naumanni en Crau en période de reproduction et pot-reproduction. Alauda 68:177-184

Madroño A, González C, Atienza JC (eds) (2004) Libro Rojo de las Aves de España. Dirección General para la Biodiversidad-SEO/BirdLife, Madrid

Manel S, Williams HC, Ormerod SJ (2001) Evaluating presence-absence models in ecology: the need to account for prevalence. J Appl Ecol 38:921-931

Perkins AJ, Maggs HE, Watson A, Wilson JD (2011) Adaptive management and targeting of agri-environment schemes does benefit biodiversity: a case study of the corn bunting Emberiza calandra. J Appl Ecol 48:514-522

Pinto M, Rocha P, Moreira F (2005) Long-term trends in great bustard (Otis tarda) populations in Portugal suggest concentration in single high quality area. Biol Conserv 124:415-423

R Development Core Team (2015) R: a language and environment for statistical computing. R Foundation for Statistical Computing, Vienna. http://www.R-project.org/

Reino L, Porto M, Morgado R, Moreira F, Fabião A, Santana J, Delgado A, Gordinho L, Cal J, Beja P (2010) Effects of changed grazing regimes and habitat fragmentation on Mediterranean grassland birds. Agric Ecosyst Environ 138:27-34

Rodr' iguez C, Johst K, Bustamante J (2006) How do crop types influence breeding success in lesser kestrels through prey quality and availability? A modelling approach. J Appl Ecol 43:587-597

Rodríguez J, Avilés JM, Parejo D (2011) The value of nestboxes in the conservation of Eurasian Rollers Coracias garrulus in southern Spain. Ibis 153:735-745

Sackl P, Tiefenbach M, Ilzer W, Pfeiler J, Wieser B (2004) Monitoring the relict population of European roller (Coracias garrulus) - a review of preliminary data and conservation implications. Acrocephalus 25:51-57

Samwald O, Štumberger B (1997) Roller Coracias garrulus. In: Hagemeijer WJM, Blair MJ (eds) The EBCC atlas of European breeding birds: their distribution and abundance. T \& AD Poyser, London, pp 436-437 
Santana J, Reino L, Stoate C, Borralho R, Carvalho CR, Schindler S, Moreira F, Bugalho MN, Ribeiro PF, Santos JL, Vaz A, Morgado R, Porto M, Beja P (2014) Mixed effects of long-term conservation investment in Natura 2000 farmland. Conserv Lett 7:467-477

Stephens DW, Krebs JR (1986) Foraging theory. Princeton University Press, Princeton

Sutherland WJ, Green RE (2004) Habitat assessment. In: Sutherland WJ, Newton I, Green RE (eds) Bird ecology and conservation: a handbook of techniques. Oxford University Press, Oxford, pp 233-249

QGIS Development Team (2015) QGIS Geographic Information System. Open Source Geospatial Foundation Project. http://qgis.osgeo.org

Tschirley A (2013) Drivers of population heath in the European roller (Coracias garrulous) in Castro Verde, Portugal. Master thesis in Applied Ecology \& Conservation, University of East Anglia, UK

Whittingham MJ (2011) The future of agri-environmental schemes: biodiversity gains and ecosystem service delivery? J Appl Ecol 48:509-513

Wolff A (2005) Influence of landscape and habitat heterogeneity on the distribution of steppe-land birds in Crau, southern France. In: Bota G, Morales MB, Mañosa S, Camprodon J (eds) Ecology and conservation of steppe-land birds. Lynx Edicions, Barcelona, pp 141-168

Worton B (1989) Kernel methods for estimating the utilization distribution in home-range studies. Ecology 70:164-168 